\title{
Postoperative infections after oesophageal resections: the role of blood transfusions
}

\author{
Francesca Rovera*, Gianlorenzo Dionigi, Luigi Boni, Andrea Imperatori, \\ Alessandra Tabacchi, Giulio Carcano, Mario Diurni and Renzo Dionigi
}

Address: Department of Surgical Sciences, University of Insubria, Varese, Italy

Email: Francesca Rovera* - francesca.rovera@uninsubria.it; Gianlorenzo Dionigi - gianlorenzo.dionigi@uninsubria.it; Luigi Boni - luigi.boni@uninsubria.it; Andrea Imperatori - andrea.imperatori@uninsubria.it;

Alessandra Tabacchi - francesca.rovera@uninsubria.it; Giulio Carcano - giulio.carcano@uninsubria.it; Mario Diurni - mdiurni@yahoo.com; Renzo Dionigi - renzo.dionigi@uninsubria.it

* Corresponding author

Published: 21 November 2006

World Journal of Surgical Oncology 2006, 4:80 doi:10.1 186/1477-7819-4-80

This article is available from: http://www.wjso.com/content/4/I/80

(c) 2006 Rovera et al; licensee BioMed Central Ltd.

This is an Open Access article distributed under the terms of the Creative Commons Attribution License (http://creativecommons.org/licenses/by/2.0), which permits unrestricted use, distribution, and reproduction in any medium, provided the original work is properly cited.

\begin{abstract}
Background: Perioperative blood transfusion carries numerous potential risks concerning the transmission of infective diseases and immunodepression that can facilitate the occurrence of postoperative infectious complications. Explanation of connections between perioperative blood transfusion and postoperative septic complication worldwide is not well documented. Many studies have described a correlation between perioperative blood transfusions and postoperative infections. On the contrary, other studies indicate that factors influencing the need for blood transfusions during surgery have a greater bearing than blood transfusion per se on the occurrence of postoperative complications.
\end{abstract}

Patients and methods: A prospective study was conducted in our Department on 110 consecutive patients undergoing oesophageal resection for primary cancer, in order to evaluate the incidence of postoperative infections related to perioperative allogenic blood transfusions. For each patient we preoperatively recorded in a computerized data-base several known risk-factors for postoperative infections; in detail we registered the administration of allogenic perioperative blood transfusions (period of administration, number of packages administered).

Results: Among the enrolled II 0 patients, 53 (48\%) received perioperative blood transfusions: in this group postoperative infections (overall infective complications) occurred in 27 patients. After a multivariate analysis we observed that perioperative blood transfusions significantly affected as an independent variable the development of wound infections $(p=0.02)$.

Conclusion: Blood transfusions independently affected the incidence of wound infections in patients who underwent oesophageal resection for primary cancer.

\section{Background}

Nosocomial infections are the most frequent complications observed in surgical oncological patients; despite considerable progress in the areas of prevention, diagnosis and therapy, postoperative infections continue to be associated with significant morbidity, sometimes with 
mortality and with extra expense to cover cost of antibiotics, blood derivatives, nursing, additional surgical procedures and prolonged hospitalization [1-3].

Most surgical infections are acquired intraoperatively and are endogenous, arising from the flora of the patient's skin, gastrointestinal tract or mucous membranes. Exogenous infections are less common and are probably acquired from the skin or nasal flora of the operating team, or more rarely from contaminated material or instruments in the operating theatre.

The risk of postoperative surgical infections is mainly related to the magnitude of surgical field contamination. The opening of the lumen of the organ containing bacteria always involves a relevant risk for postoperative wound infections. In 1964, Altemeier and the National Research Council [4] proposed a classification of surgical procedures related to the degree of bacterial contamination. This wound classification scheme has served as the basis for recommending antibiotic use, for preoperative bowel preparation, for directing wound management and for focusing wound surveillance.

Surveillance studies using classification of surgical procedures related to operative field contamination showed large variations in postoperative infection rates among different Centres, for the same type of procedures. These discrepancies led to the identification of other risk factors that might significantly influence the occurrence of infectious complications. It is through the control of such factors that better clinical results may be achieved.

These other factors affecting the incidence of postoperative infections have been identified through clinical and experimental studies carried out during the last decades; these may be divided into two groups: treatment-related and patient-related. The first group includes quality of surgical care, type and duration of surgery, emergency procedure, immunosuppressive therapy, blood transfusions. The second group comprises advanced age, co-morbidity, pre-existing infections, malnutrition and host defence deficiency.

Perioperative blood transfusion carries numerous potential risks concerning the transmission of infective diseases and immunodepression that can facilitate the occurrence of postoperative infectious complications. Explanation of relation between perioperative blood transfusion and postoperative septic complication is not well documented.

Many studies have described a correlation between perioperative blood transfusions and postoperative infections [5-10], suggesting that blood transfusion interferes with the immune system of the recipient; thus transfusionrelated immunomodulation may have an impact on host defence and on the clinical course of patients who received blood components. Firstly, the immunosuppressive effects of allogeneic blood were noticed in 1973, when it was shown that renal transplant survival was improved in a group who received blood transfusions. Since then, several clinical studies, comparing groups of patients which needed perioperative blood transfusions with non-transfused patients, were carried out to evaluate the real immunosuppressive mechanism and its relationship with postoperative infectious complications. Moreover, studies evaluating the correlation between the amount of transfused blood units with infective complications demonstrated dose-related effect [11,12].

On the other hand, other studies indicate that factors influencing the need for blood transfusions during surgery have a greater bearing than blood transfusion per se on the occurrence of postoperative complications $[13,14]$. In fact, those clinical studies underlying the relationship between blood transfusion and postoperative infective complications have difficulties in being adjusted for the effects of many confounding variables related to the severity of illness, the various risk-factors for infections at specific sites and the surgical procedure.

Nevertheless, a meta-analysis recently published and some larger observational studies, in which Authors tried to make adjustments for many potentially confounding variables, came to the conclusion that this correlation exists [15-17].

Prospective studies investigating the association between blood transfusions and postoperative infections are needed, to justify more accurately the indications for blood transfusions.

\section{Aims of the study}

A prospective study was conducted in our Department of Surgical Sciences of University of Insubria in Varese, between August 1987 and January 2005, on 110 consecutive patients undergoing oesophageal resection for primary cancer. The purposes of this prospective study were to set up a data bank on surgical infections observed, in order to systematically register such infections complications; to observe the incidence of postoperative infections related to perioperative blood transfusions.

\section{Patients and methods}

We prospectively studied 110 consecutive patients admitted to our Institute and undergoing resection for oesophageal cancer performed by the same surgical team. The average age was $62 \pm 9$ years (range 38-80); 92 were male and 18 female. 
For each patient, we preoperatively recorded in a computerized data-base the following risk-factors: diabetes, steroid therapy, obesity, chronic renal failure, cirrhosis, preexisting chronic pulmonary disease, neoadjuvant radiochemotherapy, nutritional and immunological parameters such as serum albumin and lymphocyte count.

Postoperatively, we prospectively monitored patients daily recording the development of infective complications such as pneumonia, wound infection, urinary tract infection, as well as septic complications and the presence of abdominal abscess and anastomotic leakage.

The type of operation, the duration of surgery, the preoperative hospitalization, the need of antibiotic therapy, the postoperative hospital stay were also registered. A careful monitoring and registration of perioperative blood transfusions (number of units and period of administration) was done.

According to the classification proposed by Altemeier and the National Research Council, in the absence of pre-existing thoracic or abdominal infection and if the surgical procedure is carried out with skilled technique, the oesophageal resection is considered a clean-contaminated procedure, because there is a surgical opening of the oesophagus and subsequent anastomosis, with controlled contamination of the surgical field.

\section{Analysis of results and statistical methods}

The significance of any difference in the characteristics of the oesophageal cancer patients was evaluated. Where differences were found Cox's proportional hazard regression (univariate and multivariate analysis) was used to identify independent predictors of postoperative infections.

Data were expressed as mean with standard deviation or median and range according to the data distribution. Student's $t$ test was used for analysis of continuous data and the chi-square test was used to compare differences between proportions. Mann-Whitney U Test was used to compare median values. P-values $<0.05$ were considered significant. Statistical package for social sciences (SPSS version 11.0, MapInfo Corporation, Troy, NY, USA) was used for data analysis.

\section{Results}

After resection of the oesophageal cancer, surgical reconstruction was obtained by oesphago-gastric stapled anastomosis in 107 patients (97\%; 20 cervical and 87 thoracic), oesophago-digiunal anastomosis in 2 patients and an anastomosis with pharynx in 1 patient.

Out of 110 patients, $12(11 \%)$ had wound infections, 19 $(17 \%)$ pulmonary infections; $10(9 \%)$ urinary tract infections; 15 (14\%) intra abdominal abscess and anastomotic leakage. The perioperative mortality was $2.7 \%$ (3 patients). Table 1 shows biochemical data related to the development of surgical infections.

Among the enrolled 110 patients, 53 (48\%) received perioperative blood transfusions, with an average number of blood units transfused per patient of $1.5 \pm 2$ (range 1-12). In all these patients blood transfusions were administered perioperatively (intraoperatively or in the first 48 hours from surgical procedure). In the transfused group postoperative infections (overall infective complications) occurred in 27 (51\%) compared to 20 (35\%) of infections registered in 57 non-transfused patients. In a univariate analysis this difference did not reach a statistical significance: $\mathrm{p}=0.093$ (Table 2).

After a multivariate analysis we observed that perioperative blood transfusions was an independent variable for the development of wound infections $(\mathrm{p}=0.02)$, while the development of postoperative infection, pulmonary infections, urinary tract infections and anastomotic dehiscence with abscess were not significantly influenced by blood transfusions as independent factor ( $\mathrm{p}$-value 0.11 ; $0.93 ; 0.13$ and 0.82 respectively). The microorganisms frequently isolated from different cultural samples are detailed in tables 3, 4 and 5 .

\section{Discussion}

In the last decade the immunosuppressive effect of blood transfusion has been studied in detail.

Table I: Association between continuous variables and postoperative infections

\begin{tabular}{|c|c|c|c|}
\hline & $\begin{array}{l}\text { Patients who developed infections }(N=47) \\
\text { (Mean } \pm S D)\end{array}$ & $\begin{array}{c}\text { Patients who did not develop infections }(\mathrm{N}=63) \\
(\text { Mean } \pm \mathrm{SD})\end{array}$ & $\mathrm{P}$-value \\
\hline Haemoglobin (g/dl) & $13.5 \pm 2$ & $13.5 \pm 2$ & NS \\
\hline Haematocrit (\%) & $39.8 \pm 4.8$ & $40.6 \pm 5.6$ & NS \\
\hline Serum albumin $(g / d l)$ & $3.9 \pm 0.4$ & $3.9 \pm 0.7$ & NS \\
\hline Blood lymphocytes level $/ \mathrm{mm}^{3}$ & $1766 \pm 764$ & $1869 \pm 790$ & NS \\
\hline Preoperative hospital stay (days) & $15.8 \pm 12.6$ & $12 \pm 7$ & 0.057 \\
\hline Postoperative hospital stay (days) & $15.8 \pm 12.6$ & $17.9 \pm 12.7$ & NS \\
\hline Length of operation (min) & $300 \pm 87$ & $276 \pm 99$ & NS \\
\hline
\end{tabular}


Table 2: Incidence of postoperative infections in transfused and non transfused patients (univariate analysis)

\begin{tabular}{lccc}
\hline & Patients who received transfusions $(\mathrm{n}=53)$ & Patients who did not receive transfusions $(\mathrm{n}=57)$ & $\mathrm{p}$-value \\
\hline \# patients with a postoperative infection & 27 & 20 & 0.093 \\
Wound infections & 8 & 4 & 0.175 \\
Respiratory infections & 10 & 9 & 0.670 \\
Urinary tract infections & 9 & 1 & 0.005 \\
Abscess/anastomotic leakage & 9 & 6 & 0.324 \\
\hline
\end{tabular}

During the early nineties a large number of patients who underwent major surgical procedures received blood transfusions, several studies were carried out to investigate whether homologous blood transfusions significantly affect postoperative septic morbidity and mortality [18]. Clinical effects of transfusion-induced immunosuppression in surgical patients have been largely debated in the literature with contradictory results.

The immunosuppressive effect is supported when considering the lower degree of allogeneic transplant rejection and a higher frequency of cancer recurrence in patients who underwent blood transfusions [19].

Historically, Opelz and Terasaki demonstrated that blood transfusions before surgery of kidney transplant may prolong graft survival. Likewise, it was noticed that blood transfusions seemed to prevent recurrent abortions and led to lower recurrence rates in Crohn's disease and, nowadays, several studies support the hypothesis that allogeneic blood transfusion is an independent risk-factor for the development of postoperative bacterial infection $[20,21]$. Transfusion-induced immunosuppression is thought to mediate this effect $[22,23]$.

Three mechanisms are mainly involved in blood transfusions associated with infections: 1) direct transmission of the infection from donor to recipient through blood micro-organisms; 2) activation of pre-existant or latent recipient infection; and 3) activation of recipient immunity defence.

Immunological alterations following blood transfusion can produce a clinical effect.

Table 3: More frequent microorganisms isolated from infected wound

\begin{tabular}{lc}
\hline Type of microorganism & \# patients \\
\hline Escherichia coli & 8 \\
Staphylococcus aureus & 6 \\
Pseudomonas aeruginosa & 3 \\
Enterococcus faecium & 2 \\
Staphylococcus epidermidis & 2 \\
Enterococcus faecalis & 1 \\
\hline
\end{tabular}

Blood transfusion may interfere with the immunological response interacting with macrophages and with lymphocytes. These cells play a primary role in wound and anastomotic healing in the postoperative period, and raise the incidence of peri-anastomotic abscess and generalized peritonitis $[24,25]$.

In fact it is documented that blood transfusions may delay wound and anastomotic healing by interfering with the specific actions of these cells. Moreover, blood transfusions in patients who underwent nephrodyalisis blocked the lymphocytic response toward different mitogenic and antigenic molecules; suppressor lymphocytes were enhanced and an inverted ratio between T-helper and Tsuppressor lymphocytes was observed [26].

Prolonged T- lymphocytes suppression after blood transfusion in patients with chronic inflammatory bowel disease was reported [27]. Lymphocytic response to phitohaemo-agglutinin, concavalin A and such antigen was seen for a period of 4 weeks following blood transfusion in abdominal and thoracic surgery.

Blood transfusion has also been identified as a high riskfactor of complications in emergency surgery for bowel perforation related to abdominal blunt trauma [5]. The direct relationship between the number of blood units transfused and better survival was also documented [2830].

Table 4: More frequent microorganisms isolated from sputum in patients with respiratory infections

\begin{tabular}{lc}
\hline Type of microorganism & \# patients \\
\hline Pseudomonas aeruginosa & 12 \\
Staphylococcus aureus & 9 \\
Candida species & 5 \\
Escherichia coli & 3 \\
Enterobacter cloacae & 2 \\
Stenotrophomonas maltophilia & 2 \\
Staphylococcus epidermidis & 1 \\
Haemophilus influenzae & 1 \\
Enterococcus faecalis & $\mathrm{I}$ \\
\hline
\end{tabular}


Table 5: More frequent microorganisms isolated from urine in patients with urinary tract infections

\begin{tabular}{lc}
\hline Type of microorganism & \# patients \\
\hline Enterococcus faecalis & 2 \\
Enterococcus faecium & 2 \\
Escherichia coli & 2 \\
Staphylococcus aureus & $\mathrm{I}$ \\
Enterobacter cloacae & $\mathrm{I}$ \\
Staphylococcus epidermidis & $\mathrm{I}$ \\
Candida species & $\mathrm{I}$ \\
\hline
\end{tabular}

Also the timing of administration seems to be relevant. Several Authors documented that the immunosuppressive effect of blood transfusion is greater when it is given intraoperatively or in the immediate postoperative period (within the first 48-72 hours from surgical procedure). Bellantone et al., reported a likely association between postoperative infections and postoperative transfusion [31].

Despite the above mentioned clinical studies seem to correlate blood transfusion as an independent risk-factor to postoperative complications, a causal relationship between blood transfusion and an increase in the risk of postoperative infection is hard to prove in the clinical setting, firstly because obviously these are not randomized studies and secondly for the doubtful role of too many confounding variables. It is based on these considerations that some authors proposed that the detection of a relationship between postoperative infections and perioperative blood transfusions may depend on many patient and surgical variables that may complicate interpretation of the results; indeed, it remains to be elucidated whether blood transfusion is an independent variable causing surgical infections, or it is a variable dependant on other more important risk-factors (i.e. anemia) [13].

After a careful multivariate analysis we observed a higher number of postoperative wound infections in patients that received perioperative blood transfusions compared with patients that did not $(\mathrm{p}=0.02)$. Eight out of twelve patents $(67 \%)$ who developed this kind of postoperative complication received blood transfusions. Blood transfusions independently affected the incidence of wound infections in patients who underwent oesophageal resection for primary cancer.

\section{Conclusion}

The results of our study are similar to those obtained by other studies that came to the same conclusions we support a cautious interpretation of the effects of perioperative blood transfusions on postoperative infective complications. The blood transfusion may induce immunomodulation and consequently immunodepression so whenever possible perioperative blood transfusion has to be limited.

\section{Competing interests}

The author(s) declare that they have no competing interests.

\section{Authors' contributions}

FR and AT: acquisition of data, GD, MD and AI: study conception and design, GC and LB: analysis and interpretation of data, FR: drafting of manuscript, RD: critical revision and supervision

\section{Acknowledgements}

The Authors are grateful to professor Raffaele Novario (Department of Clinical and Biological Sciences, University of Insubria, Varese) for support in the statistical analysis and interpretation of data.

\section{References}

I. Tsutsui S, Moriguchi S, Morita M: Multivariate anaysis of postoperative complications after esophageal resection. Ann Thorac Surg 1992, 53:1052-1056.

2. Bartels $\mathrm{H}$, Stein HJ, Siewert JR: Preoperative risk analysis amnd postoperative mortality of oesophagectomy for respectable oesophageal cancer. Br J Surg 1998, 85:840-844.

3. Whooley BP, Law S, Murthy SC, Alexandrou A, Wong J: Analysis of reduced death and complication rates after esophageal resection. Ann Surg 200I, 233:338-344.

4. Altemeier WA, Burke JF, Pruitt BA Jr, Sandusky WR: Manual on control of infection in surgical patients Second edition. JB Lippincott Co., Philadelphia; 1984.

5. Nichols RL, Smith JW, Klein DB, Trunkey DD, Cooper RH, Adinolfi MF, Mills J: Risk of infection after penetrating abdominal trauma. N Engl ] Med 1984, 3 I I: 1065-1070.

6. Tartter PJ, Quintero S, Barron DM: Perioperative blood transfusion associated with infectious complications after colorectal cancer operations. Am J Surg 1986, 152:479-482.

7. Edna TH, Bjerkeset T: Association between transfusion of stored blood and infective bacterial complications after resection for colorectal cancer. Eur J Surg 1998, 164:449-456.

8. Braga M, Vignali A, Radaelli G, Gianotti L, Di Carlo V: Association between perioperative blood transfusion and postoperative infection in patients having elective operations for gastrointestinal cancer. Eur J Surg 1992, I 58:53 I-536.

9. Tang R, Chen HH, Wang YL, Changchien CR, Chen JS, Hsu KC, Chiang JM, Wang JY: Risk factors for surgical site infection after elective resection of the colon and rectum: a single-center prospective study of $\mathbf{2 , 8 0 9}$ consecutive patients. Ann Surg 200I, 234: I8I-I89.

10. Innerhofer P, Klingler A, Klimmer C, Fries D, Nussbaumer W: Risk for postoperative infection after transfusion of white blood cell-filtered allogeneic or autologous blood components in orthopaedic patients undergoing primary arthroplasty. Transfusion 2005, 45:103-II0.

II. Leal-Noval SR, Marquez-Vácaro JA, Garcia-Curiel A, Camacho-Laraña $P$, Rincón-Ferrari MD, Ordoñez-Fernández A, Flores-Cordero JM, Loscertales-Abril J: Nosocomial pneumonia in patients undergoing heart surgery. Crit Care Med 2000, 28:935-940.

12. Kinoshita $Y$, Udagawa $H$, Tsutsumi $K$, Ueno M, Nakamura T, Akiyama $H$, Takahashi K, Kajiyama $Y$, Tsurumaro M: Usefulness of autologous blood transfusion for avoiding allogenic transfusion and infectious complications after esophageal resection. Surgery 2000, I 27: 185-192.

13. Jahnson S, Andersson M: Adverse effects of perioperative blood transfusion in patients with colorectal cancer. Eur J Surg 1992, 158:419-425.

14. Mynster T, Christensen IJ, Moesgaard F, Nielsen HJ: Effects of the combination of blood transfusion and postoperative infectious complications on prognosis after surgery for colorectal 
cancer. Danish RANX05 Colorectal Cancer Study Group. $\mathrm{Br}$ J Surg 2000, 87:1553-1562.

15. Hill GE, Frawley WH, Griffith KE, Forestner JE, Minei JP: Allogeneic blood transfusion increases the risk of postoperative bacterial infection: a meta-analysis. J Trauma 2003, 54:908-914.

16. Carson Jl, Altman DG, Duff A, Noveck H, Weinstein MP, Sonnenberg FA, Hudson JI, Provenzano G: Risk of bacterial infection associated with allogeneic blood transfusion among patients undergoing hip fracture repair. Transfusion 1999, 39:694-700.

17. Chang H, Hall GA, Geerts WH, Greenwood C, McLeod RS, Sher GD: Allogeneic red blood cell transfusion is a independent risk factor for the development of postoperative bacterial infection. Vox Sang 2000, 78:13-18.

18. Wobbes T, Bemelmans BL, Kuypers JH, Beerthuizen GI, Theeuwes AG: Risk of postoperative septic complications after abdominal surgical treatment in relation to perioperative blood transfusion. Surg Gynecol Obstet 1990, 1 71 1:59-62.

19. Karl RC, Schreiber R, Boulware D, Baker S, Coppola D: Factors affecting morbidity, mortality, and survival in patients undergoing Ivor Lewis esophagogastrectomy. Ann Surg 2000, 23 I:635-643.

20. Houbiers JG, van de Velde CJ, van de Watering LM, Hermans J, Schreuder S, Biinen AB, Pahlplatz P, Schattenkerk NE, Wobbes T, de Vries JE, Klementschitsch P, van de Maas AH, Brand A: Transfusion of red cells is associated with increased incidence of bacterial infection after colorectal surgery: a prospective study. Transfusion 1997, 37: 126-134.

21. Tartter PI: Blood transfusion and infectious complications following colorectal cancer surgery. Br J Surg 1988, 75:789-792.

22. Waymack JP, Balakrishnan K, McNeal N, Gonce S, Miskell P, Warden GD, Alexander JW: Effect of blood transfusions on macrophage-lymphocyte interaction in an animal model. Ann Surg 1986, 204:68I-685.

23. Waymack JP, Gallon L, Barcelli U, Trocki O, Alexander JW: Effect of blood transfusions on immune function. Alterations in macrophage arachidonic acid metabolism. Arch Surg 1987, I 22:56-60.

24. Tadros T, Wobbes T, Hendriks T: Blood transfusion impairs the healing of experimental intestinal anastomoses. Ann Surg 1992, 21 5:276-281.

25. Alves A, Panis Y, Trancart D, Regimbeau JM, Pocard M, Valleur P: Factors associated with clinically significant anastomotic leakage after large bowel resection: multivariate analysis of 707 patients. World J Surg 2002, 26:499-502.

26. Kaplan J, Sarnaik S, Gitlin J, Lusher J: Diminished helper/suppressor lymphocyte ratios and natural killer activity in recipients of repeated blood transfusion. Blood 1984, 64:308-310.

27. Tartter PI, Heimann TM, Aufses AH Jr: Blood transfusion, skin test reactivity and lymphocytes in inflammatory bowel disease. Am J Surg | 986, I5 I:358-361.

28. Opelz G, Sengar DPS, Mickey MR, Terasaki P: Effect of blood transfusions on subsequent kidney transplants. Transplant Proc 1973, 5:253-259.

29. Salvatierra O Jr, Vincenti F, Amend W, Potter D, Iwaki Y, Opelz G, Terasaki P, Duca R, Cochrum K, Hanes D, Stoney RJ, Feduska NJ: Deliberate donor-specific blood transfusions prior to living related renal transplantation. A new approach. Ann Surg 1980, 1 92:543-552.

30. Takemura M, Osugi $\mathrm{H}$, Higashino M, Takada N, Lee S, Kinoshita $\mathrm{H}$ : Effect of substituting allogenic blood transfusion with autologous blood transfusion on outcomes after radical oesophagectomy for cancer. Ann Thorac Cardiovasc Surg 2005, I I:293-300.

31. Bellantone R, Sitges-Serra A, Bossola M, Doglietto GB, Malerba M, Franch G, Pacelli F, Crucitti F: Transfusion timing and postoperative septic complications after gastric cancer surgery: a retrospective study of 179 consecutive patients. Arch Surg 1998 133:988-992.

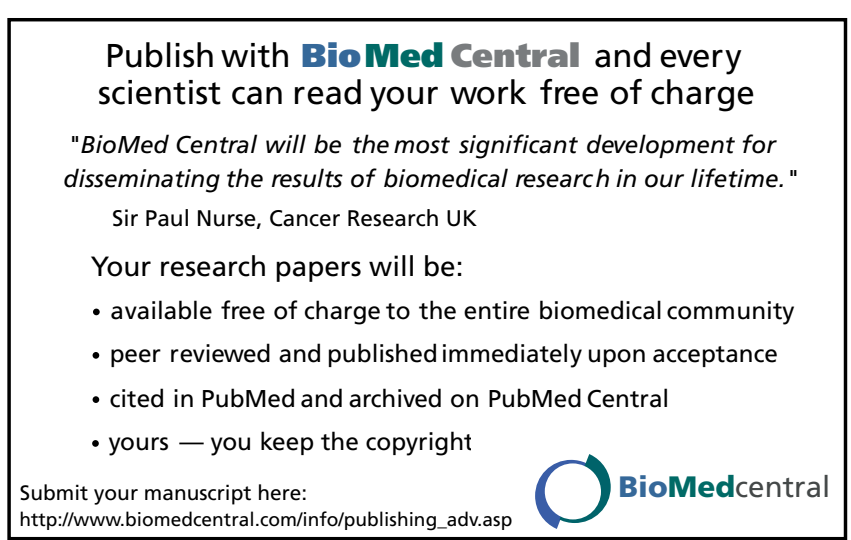

